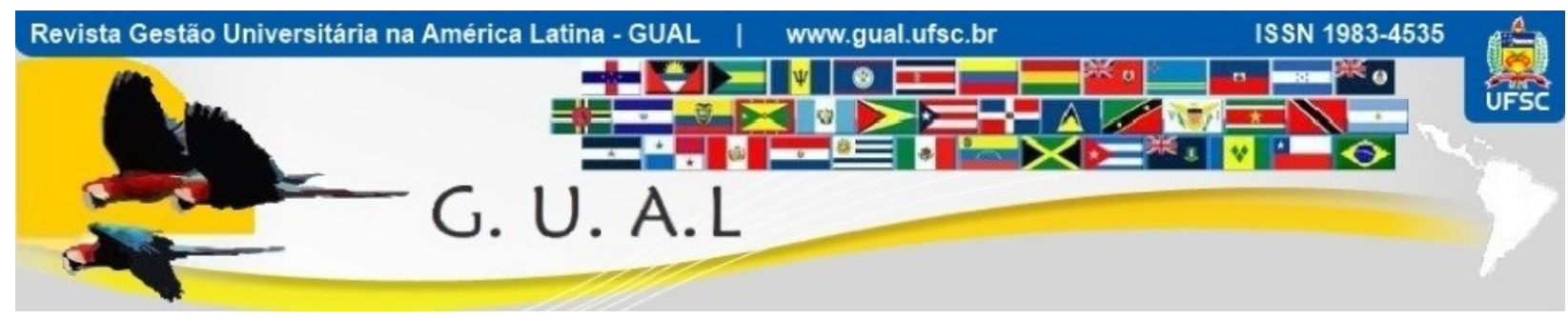

DOI: http://dx.doi.org/10.5007/1983-4535.2016v9n3p292

\title{
MBA - O QUE ALUNOS E EX-ALUNOS PENSAM A RESPEITO DO CURSO REALIZADO, SEU APRENDIZADO, E DO IMPACTO EM SUAS CARREIRAS
}

\section{MBA - WHAT STUDENTS AND ALUMNI THINK ABOUT THE ACCOMPLISHED COURSE, THEIR LEARNING, AND THE IMPACT ON THEIR CAREERS}

Patrícia Teixeira Maggi da Silva, Mestre

Faculdade Sumaré patriciatmaggi@gmail.com

Arilda Schmidt Godoy, Doutora Universidade Presbiteriana Mackenzie - UPM arildagodoy@gmail.com

Recebido em 21/julho/2014

Aprovado em 13/junho/2016

Sistema de Avaliação: Double Blind Review

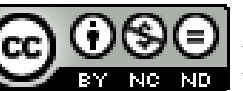

Esta obra está sob uma Licença Creative Commons Atribuição-Uso. 


\title{
RESUMO
}

O MBA é um dos programas mais populares em educação gerencial nos dias atuais. Pesquisas conduzidas pelos órgãos acreditadores e por revistas especializadas e internacionalmente reconhecidas publicam periodicamente rankings de cursos e escolas com o objetivo de avaliar os aspectos objetivos relacionados ao MBA, entre eles: aumentos salariais, promoções, carreira e empregabilidade. O MBA também vem sofrendo críticas, destacando-se a falta de alinhamento de seu curriculum às necessidades do mundo dos negócios e a real contribuição para o desenvolvimento de gestores capazes de lidar com os desafios e a complexidade do ambiente de negócios contemporâneo. No esforço de ampliar a compreensão acerca do MBA, este artigo tem como objetivo descrever, sintetizar e analisar o que os alunos pensam sobre o MBA, destacando-se como eles avaliam o curso, o seu aprendizado e quais os impactos em suas carreiras. No plano empírico, realizou-se uma pesquisa qualitativa, com entrevistas semiestruturadas com 13 alunos de MBAs com especialização de uma instituição de ensino superior na cidade de São Paulo. Os resultados apontam avaliações positivas com relação ao curso e à aprendizagem e que o MBA por si só não garante ascensão de carreira e empregabilidade.

Palavras-chave: Educação gerencial. MBA. MBA no Brasil.

\begin{abstract}
The MBA is one of the most popular programs in management education today. Research conducted by accreditors organizations and specialized and internationally recognized journals regularly publish rankings of courses and schools to evaluate objective aspects related to MBA, including: salary increases, promotions, career and employability. The MBA also has been criticized, especially the lack of aligning of its curriculum to the needs of the business world and the real contribution to the development of managers able to deal with the challenges and the complexity of the contemporary business environment. In an effort to increase the understanding of the MBA, this article aims to describe, analyze and synthesize what students think about the MBA, highlighting how they evaluate the course, their learning and the impact on their careers. Empirically, we carried out a qualitative study with semistructured interviews with 13 students of MBA with specialization of an institution of higher education in the city of São Paulo. The results indicate positive reviews about the course and the learning and the MBA alone does not guarantee rise of career and employability.
\end{abstract}

Keywords: Management education. MBA. MBA in Brazil. 


\section{INTRODUÇÃO}

Entre os programas formais para os indivíduos que buscam melhorar suas habilidades gerenciais, o MBA é provavelmente o mais popular nos dias atuais. Muitos indivíduos buscam no MBA o desenvolvimento de conhecimentos e habilidades, que lhes possibilitarão ocupar posições gerenciais em diferentes contextos organizacionais. Consequentemente, grande parte da literatura sobre educação gerencial tem como foco os cursos de MBA e sua contribuição para o desenvolvimento de gerentes.

Nos últimos anos, no Brasil, foi possível verificar um crescimento na oferta de cursos de pós-graduação em Administração, com destaque para os MBAs, o que torna relevante o exame de como esses programas vem sendo desenvolvidos e avaliados. A relevância e a preocupação em avaliar o MBA, tanto no Brasil como em outros países, é reforçada pelas críticas sobre a real efetividade desses programas para o desenvolvimento de gestores. Ao analisar as ideias dos pesquisadores internacionais (PFEFFER; FONG, 2003; MINTZBERG, 2004; BENNIS; O’TOOLE, 2005) e nacionais (RUAS, 2003; WOOD JR.; PAULA, 2004), é possível sintetizar a ideia principal desses críticos numa pergunta: "os profissionais que possuem MBA são capazes de lidar com a complexidade do atual ambiente de negócios?”.

Para os pesquisadores internacionais (PFEFFER; FONG, 2003; MINTZBERG, 2004; BENNIS; O’TOOLE, 2005), as críticas ao MBA estão voltadas, especialmente, à concepção do seu modelo, aos critérios de seleção dos alunos, à incapacidade deles em transferir o conhecimento obtido para situações reais da prática organizacional e à falta de alinhamento do seu conteúdo às necessidades e desafios das organizações.

Na opinião dos pesquisadores brasileiros, (RUAS, 2003; WOOD JR.; PAULA, 2004), o diferencial competitivo no mercado de trabalho, a empregabilidade e os aumentos salariais obtidos pelos profissionais egressos dos MBAs não mais se verificam, em função do crescimento da oferta, demanda e popularização do título de MBA no país.

Apesar das críticas, os MBAs ainda fazem parte das ações de educação formal dos profissionais que aspiram a cargos gerenciais e executivos e daqueles que já são gerentes e buscam seu desenvolvimento. Possuir um diploma de MBA é visto como chave para a função gerencial, tanto no Brasil, quanto em outros países. Neste sentido, Rubin e Diedorff (2009, p. 218) constatam que “... apesar da recente enxurrada de críticas, os alunos de MBA continuam a afirmar que a sua decisão em fazer o curso foi a correta”. Segundo Brocklerurst et al. (2007, p. 391): 
Os tradicionais apoiadores do MBA concordam que ele é uma qualificação verdadeiramente internacional reconhecida em todo o mundo. Adicionalmente, os cursos de MBA reunem um corpo estudantil rico e diversificado, muito mais que outras qualificações. Assim, ele ajuda as multinacionais e outras empresas a atender às demandas de uma economia globalizada.

É possível perceber que o MBA enquanto um programa de educação gerencial é cercado de polêmicas e contradições, embora como mostram Wood Jr. e Paula (2004), a indústria do management, na qual o MBA está incluído, seja reconhecida como um fenômeno relevante, com impactos sobre a prática gerencial e a vida social. Os resultados (muitas vezes divergentes) das pesquisas sobre MBA remetem à opinião de Cheng (2000) de que tanto acadêmicos quanto profissionais ainda não analisaram os reais efeitos do MBA no desempenho do trabalho. Hay (2006) corrobora essa ideia afirmando que, apesar das críticas que tais programas vêm recebendo, pouco se sabe a respeito de sua real contribuição em termos de aprendizagem e seu efeito sobre as práticas organizacionais. Também para Zhao et al (2006), a literatura sobre o tema tem apresentado resultados inconsistentes e pontos de vista controversos. Neste sentido, é necessário ampliar o escopo desses estudos, por meio da avaliação dos próprios alunos como seus beneficiários, como proposto na presente pesquisa.

Segundo Baruch e Leeming (2001), existem três tipos de participantes envolvidos nos cursos de MBA: (a) o indivíduo, primeiro no papel de estudante e depois como graduado; (b) a organização no papel de um futuro empregador, ou enviando empregados com potencial gerencial para fazer o MBA; e (c) as escolas de negócio, como responsáveis pela criação de um programa adequado. Considerando estes três segmentos é necessário, para estes autores, avaliar a opinião dos alunos sobre o real valor proporcionado pelo MBA, em termos de desenvolvimento de carreira, empregabilidade, competências e conhecimentos sobre gestão.

Além disso, é importante destacar que os programas de MBA geralmente propõem o desenvolvimento do conhecimento acadêmico e uma abordagem analítica para a solução de problemas gerenciais e da habilidade de abordar novos problemas de forma estruturada. Também implicam em altos custos, quando comparados a outros cursos de pós-graduação lato sensu. Portanto, verificar se esses programas realmente atingem seus principais objetivos implica também a análise de como seus alunos o avaliam.

Em função do baixo número de pesquisas de MBA que levem em consideração as especificidades e as diferenças do MBA brasileiro (CRUZ, 2013), e de pesquisas que avaliam o MBA com o uso de abordagens qualitativas, como proposto por Pham (2011), este artigo 
apresenta os resultados de uma pesquisa empírica que buscou preencher estas duas lacunas. Seu objetivo geral foi identificar, sintetizar e analisar o que os alunos de cinco MBAs com especialização de uma Instituição de Ensino Superior (IES) localizada na cidade de São Paulo pensam a respeito do curso, os impactos do mesmo em suas carreiras e empregabilidade. A apresentação do artigo está estruturada da seguinte forma: na segunda seção, expõe-se o referencial teórico com as características mais significativas do MBA, classificando o mesmo como um programa de educação gerencial, além das principais críticas que ele vem recebendo. Na terceira seção, aborda-se a metodologia utilizada para desenvolver a pesquisa. $\mathrm{Na}$ quarta seção, são descritos e analisados os resultados encontrados e, por fim, as principais conclusões, limitações e sugestões para futuras pesquisas.

\section{REFERENCIAL TEÓRICO}

2.1 O MBA COMO PROGRAMA DE EDUCAÇÃO GERENCIAL: DEFINIÇÃO, BREVE HISTÓRICO E PRINCIPAIS CRITÉRIOS

De acordo com os critérios de certificação definidos pela AMBA (Association of $M B A s)$, o MBA é um programa de pós-graduação generalista em nível de mestrado. $\mathrm{O}$ currículo do curso deve estar focado no desenvolvimento de liderança, na gestão em nível estratégico da organização e no desenvolvimento da carreira profissional, sobretudo com orientação prática. O público-alvo do MBA são os profissionais com, no mínimo, três anos de experiência profissional (AMBA, 2012).

Os MBAs foram introduzidos na Universidade de Harvard em 1908 e em Stanford em 1928 e sua popularização vem acompanhando o fenômeno de expansão dessas escolas. $\mathrm{Na}$ década de 1980 atingiram alto grau de popularidade e, no início dos anos 1990, o modelo do MBA americano já havia se espalhado pela Europa, incluindo as universidades de Cambridge e Oxford, além de universidades francesas (WOOD JR.; PAULA, 2002). Nos Estados Unidos, se tornou marca de distinção para pessoas que buscavam posições executivas nas organizações. Entre 1950 e 1975, o número de diplomas de MBA conferidos nesse país chegou a 40 mil por ano e o número de programas oferecidos chegou a aproximadamente 500 (HERRINGTON, 2010). Sua expansão foi acompanhada pelo estímulo à competição provocado pela publicação de rankings das escolas de negócio. Os rankings de revistas internacionais mais conhecidos são: Business Week, Financial Times e The Economist. 
Para Acito, McDougall e Smith (2007), os rankings divulgados na mídia devem continuar em evidência, pois são um dos principais fatores de diferenciação entre os cursos. Têm como objetivo comparar os MBAs de diferentes escolas de negócios, porém, não comparam alunos que fizeram MBA com outros que não fizeram. Segundo Acito, McDougall e Smith (2007), uma das tendências para o futuro é o crescimento da competição no mercado dos MBAs a nível mundial. Acreditam que haverá aumento no número de interessados nos cursos de tempo parcial (part-time courses), pois os alunos desejam continuar exercendo suas atividades profissionais ao mesmo tempo em que estudam. As escolas de negócio também deverão implantar mudanças e inovações significativas em seus cursos como forma de atrair novos estudantes em primeira instância, e as organizações que contratam esses alunos, em última instância. Consideram ainda o fortalecimento de programas de MBA à distância.

As disciplinas do MBA têm como objetivo oferecer aos alunos uma visão das diversas áreas de negócios: Finanças, Contabilidade, Marketing, Recursos Humanos, Gestão de Operações, entre outras.

\subsection{OS MBAS NO BRASIL}

No Brasil, o uso da sigla MBA envolve considerável polêmica, que vem acompanhando uma disseminação acelerada do nome no contexto de toda pós-graduação em Administração. Apesar de o MBA brasileiro ter sofrido grande influência do MBA norteamericano, a primeira grande diferença entre eles é que enquanto o americano é um programa de Mestrado Stricto Sensu, o brasileiro é um programa de pós-graduação Lato Sensu.

Segundo Wood Jr. e Paula (2004), houve uma adoção indiscriminada do termo MBA no Brasil, o que torna muitas vezes difícil uma análise comparativa desses programas no país com outros no exterior. Dois fatores contribuíram para a proliferação dos cursos de MBA no Brasil: a falta de uma regulamentação específica do MEC e a inexistência de um órgão privado regulador nos moldes dos encontrados no exterior (AACSB International, Executive MBA Council norteamericano, a AMBA e o EQUIS).

No Brasil, também é possível perceber o movimento dos rankings das escolas de negócio, incluindo avaliações dos MBAs. A Revista Você S/A publicou rankings e pesquisas de MBAs até o ano de 2010. Periodicamente, também são publicados cadernos especiais 
sobre pós-graduação com avaliações de escolas e cursos em jornais, como Folha de São Paulo e Valor Econômico.

\subsection{TIPOS DE MBAS}

As escolas de negócios oferecem uma variedade de modalidades de MBAs, incluindo variações no modelo original e MBAs com especialização. Com base nas definições propostas por Hunt e Speck (1986 apud GUPTA; SAUNDERS; SMITH, 2007), os principais tipos de MBA são apresentados no Quadro 1, a seguir:

\begin{tabular}{|l|l|}
\hline MBA Generalista & $\begin{array}{l}\text { Tem como objetivo desenvolver habilidades genéricas e conhecimento em gestão, } \\
\text { provendo aos estudantes conhecimento de todas as áreas de negócio e oferecendo aos } \\
\text { mesmos a oportunidade de se aprofundar em certas áreas. Estes programas são voltados } \\
\text { para gestores que ocupam posições numa área específica dentro da organização e almejam } \\
\text { posições com ampliação de suas responsabilidades. }\end{array}$ \\
\hline $\begin{array}{l}\text { MBA com } \\
\text { especializações }\end{array}$ & $\begin{array}{l}\text { Tem como objetivo oferecer um aprofundamento numa área específica (Finanças, } \\
\text { Marketing, Recursos Humanos, Tecnologia da Informação, etc.), tendo em vista a } \\
\text { necessidade de gerenciar tarefas específicas num ambiente tecnologicamente complexo. }\end{array}$ \\
\hline $\begin{array}{l}\text { MBA Generalista } \\
\text { com opções de } \\
\text { especialização }\end{array}$ & $\begin{array}{l}\text { Contempla todas as disciplinas obrigatórias do MBA generalista com a possibilidade de } \\
\text { complementação com disciplinas eletivas ou seleção de especialização numa das áreas } \\
\text { funcionais. }\end{array}$ \\
\hline $\begin{array}{l}\text { MBA com } \\
\text { especializações } \\
\text { em nichos }\end{array}$ & $\begin{array}{l}\text { Tem como objetivo oferecer um aprofundamento num nicho muito específico. Exemplos: } \\
\text { Projetos de Tecnologia da Informação, Marketing Digital, Planejamento tributário, etc. }\end{array}$ \\
\hline
\end{tabular}

Quadro 1 Tipos de MBA de acordo com áreas de conhecimento.

Fonte: adaptado pelas autoras, com base em Hunt e Speck (1986 apud GUPTA; SAUNDERS; SMITH, 2007).

Com relação à duração e às formas de aplicação propostas para os MBAs, os principais tipos são o Full Time MBA de dois anos (MBA tradicional norteamericano), Full Time MBA de um ano (adotado pelas escolas europeias) e o Part-time MBA, ou MBA em tempo parcial que é o mais encontrado na realidade brasileira, sendo objeto da investigação aqui realizada.

\subsection{MBA: PRINCIPAIS CRÍTICAS}

Na revisão de literatura sobre educação gerencial e MBA, foi possível identificar que as críticas que o MBA vem recebendo não são recentes. Segundo Wood Jr. e Paula (2004), tiveram início em meados da década de 1980, acentuando-se na década de 2000, em função do comportamento tido como pouco ético por parte de profissionais que haviam cursado MBA, alguns dos quais envolvidos em escândalos financeiros em grandes corporações nos Estados Unidos. Em 1985, Cheit (apud HERRINGTON, 2010) já afirmava que os MBAs não 
abordavam tópicos importantes, como comércio global, ética, qualidade, liderança ou os efeitos que as organizações exerciam na sociedade como um todo. Mais recentemente, Herrington (2010) considera que os alunos que concluem o MBA são muito focados em aspectos financeiros de curto prazo, em detrimento das questões humanas dos negócios, além de carecerem de habilidades de comunicação, relacionamento interpessoal e formação de equipes.

Mintzberg (2004), como um dos críticos mais contundentes aos programas de educação gerencial e, mais especificamente, aos MBAs, considera que a educação gerencial ainda não foi corretamente estudada, tendo em vista que gestão é o encontro de ciência (conhecimento sistematizado por meio de pesquisas), arte (insight, visão e intuição) e ofício (experiência e aprendizagem na prática). Autor do livro "MBA? Não, Obrigado" (tradução da versão em Inglês “Managers not MBAS”), ele considera que o MBA não desenvolve gerentes, apenas treina os alunos nas funções do negócio (Marketing, Finanças, Estratégia, Recursos Humanos, etc.). Segundo ele, um gerente não pode ser desenvolvido somente em sala de aula. Primeiramente, precisa apresentar um desempenho superior e provar que pode ser gerente e, a partir daí, desenvolver sua real capacidade de gestão.

Como relatam Monks e Walsh (2001), os programas de educação gerencial e os MBAs não estão necessariamente focados no que os gestores precisam saber para desempenhar suas funções em um ambiente de negócios de alta complexidade. Além da similaridade do conteúdo oferecido por diversas escolas, há uma falta de integração entre as disciplinas. Para esses autores, os problemas enfrentados pelas organizações não são separados em áreas, ou assuntos específicos, como acontece com as disciplinas de um MBA. Consideram que disciplinas minuciosamente desenhadas podem confundir em vez de ajudar o gestor, que precisa tomar decisões sobre problemas de grande amplitude e complexidade. Defendem a ideia de que, nos MBAs, deve haver mudanças na forma de ensinar, pois o público é composto por indivíduos adultos, que já possuem experiência profissional e devem adquirir uma abordagem crítica em relação ao conteúdo aprendido. Assim, devem ser privilegiadas abordagens que utilizem princípios da andragogia, tanto em termos de aplicação do conteúdo na prática organizacional, quanto em relação às experiências na própria sala de aula. Os autores defendem a substituição da abordagem do ensino focada no desempenho para o ensino focado no entendimento, no qual o aluno deve buscar aplicar as habilidades e os conhecimentos aprendidos em situações variadas, em detrimento de apenas obter boas notas. 
Sugerem ainda mudanças nas formas de avaliação, que deveriam ser focadas nas reais oportunidades de aplicar o conteúdo do curso a problemas enfrentados pelas organizações.

Pfeffer e Fong (2003) defendem a ideia de que adotar uma abordagem científica para o ensino de gestão pode não ser útil, tendo em vista que a prática gerencial é mais bem ensinada como uma arte, complementada por lições provenientes de experiência e orientada para ações.

Conforme Bennis e O’Toole (2005), os programas de MBA vêm enfrentado críticas por falharem na transmissão de habilidades úteis e normas de comportamento ético, não prepararem líderes e não garantirem que seus alunos consigam boas colocações no mercado de trabalho. Esses autores também afirmam que a integração do conhecimento fornecido pelas disciplinas às demandas da prática dos negócios acaba sendo responsabilidade dos alunos. Adicionalmente, as organizações avaliam que os alunos que fizeram MBA não possuem as habilidades necessárias para a gestão da organização. Ainda na opinião desses autores, o curriculum do MBA como um todo precisa ser permeado com questões multidisciplinares, éticas e práticas, que reflitam os desafios de negócios enfrentados pelos líderes atuais.

Gosling e Mintzberg (2006), ao defenderem a ideia de que gestão é prática, estabeleceram sete princípios - expostos no Quadro 2 - que constituem a base de sustentação de uma pedagogia coerente com as necessidades de educação gerencial.

A educação gerencial deveria ser restrita aos gerentes com experiência prática e estes deveriam ser selecionados com base nos resultados apresentados no desempenho da função gerencial.

Os gerentes devem conciliar as atividades de trabalho com o curso, com o objetivo de juntar a educação com a prática.

A educação gerencial deve influenciar as experiências de trabalho e vida o tanto quanto possível.

A chave da aprendizagem é o pensamento reflexivo.

A reflexão em sala de aula deve gerar impactos para a organização.

A educação gerencial é um processo de aprendizagem interativo.

Os princípios anteriores demandam profundas mudanças na arquitetura, corpo docente e pedagogia da educação gerencial.

Quadro 2 Princípios de sustentação pedagógica voltados à educação gerencial.

Fonte: adaptado pelas autoras com base em Gosling e Mintzberg (2006).

De acordo com Pham (2011), que pesquisou o fenômeno da transferência de aprendizagem em MBAs, a adoção dos princípios do construtivismo nesses programas ajuda a garantir que os alunos tenham reações positivas e maximizem sua aprendizagem.

\section{PROCEDIMENTOS METODOLÓGICOS}

Este estudo é caracterizado como qualitativo básico ou genérico. Para Merriam (1998), as características fundamentais dos estudos qualitativos básicos ou genéricos são: deve incluir 
descrição, interpretação e compreensão do fenômeno estudado; utilizar dados obtidos em entrevistas, análise de documentos e/ou observações; identificar padrões recorrentes em temas e categorias, que são utilizados para análise; e preocupar-se em compreender um fenômeno ou processo, a partir da perspectiva dos participantes da pesquisa.

$\mathrm{Na}$ literatura que investiga programas de MBA, foi possível detectar que a maioria dos estudos adotou procedimentos quantitativos, pois tinham como foco aspectos objetivos tais como salário, empregabilidade e impactos na carreira. Acredita-se que a escolha da metodologia qualitativa possibilite a ampliação dos conhecimentos a respeito do tema, identificando novos elementos e possibilidades de aprofundamento.

Como estratégia de coleta de dados, foram utilizadas entrevistas semiestruturadas que exploraram as experiências relatadas por 13 participantes de programas de MBA de uma IES de São Paulo, reconhecida a nível nacional e internacional pela qualidade de seus cursos e pesquisas. Conforme Godoy (2013), a entrevista é uma ferramenta com a qual é possível captar os significados atribuídos pelas pessoas a respeito dos fenômenos descritos, por meio do relato de suas experiências e vivências.

Os participantes do presente estudo foram selecionados segundo os seguintes critérios: alunos em fase de conclusão ou que terminaram o curso há até um ano; alunos de MBA com Especialização ou focados em indústrias ou setores específicos; e as observações de Mintzberg (2004), para quem o público-alvo do MBA deve ser composto de alunos com experiência profissional relevante, ou experiência gerencial. Entende-se que os participantes dentro do perfil proposto por Mintzberg (2004) poderiam trazer contribuições mais significativas para o entendimento dos aspectos relacionados ao curso, à sua aprendizagem e aos impactos na carreira.

Os dados obtidos nas entrevistas foram analisados por meio da análise textual interpretativa de Gil Flores (1994) e da técnica de templates proposta por King (2004). Para Gil Flores (1994, p.33), a análise de dados é definida como "o conjunto de manipulações, transformações, operações, reflexões e comprovações realizadas a partir dos dados com a finalidade de extrair significado relevante em relação a um problema de investigação". Segundo King (2004), a análise via templates consiste na produção de uma lista de códigos representando temas identificados nos dados textuais, que podem ser definidos a priori ou modificados na medida em que o pesquisador lê e interpreta os textos. Um código é uma 
identificação de um fragmento de texto que o pesquisador considera importante para sua interpretação visando alcançar os objetivos propostos para a pesquisa.

Com relação ao perfil dos entrevistados, 12 homens e uma mulher, situam-se na faixa etária dos 30 aos 57 anos, com uma média de 40 anos. Quanto aos cargos ocupados, sete são gerentes, dois são diretores, um é supervisor, um é consultor e dois são sócio proprietários. No Quadro 3, apresenta-se uma síntese dos participantes da pesquisa por tipo de MBA.

\begin{tabular}{|l|c|c|c|}
\hline \multicolumn{1}{|c|}{ Tipo de MBA } & $\begin{array}{c}\text { Momento do } \\
\text { Curso }\end{array}$ & $\begin{array}{c}\text { Quantidade de } \\
\text { entrevistados }\end{array}$ & $\begin{array}{c}\text { Legenda (referências aos } \\
\text { participantes na apresentação } \\
\text { dos resultados) }\end{array}$ \\
\hline $\begin{array}{l}\text { MBA em Gestão Estratégica e } \\
\text { Econômica de Negócios }\end{array}$ & $\begin{array}{c}\text { Em fase de } \\
\text { conclusão }\end{array}$ & 6 & $\begin{array}{c}\text { GEEN-1, GEEN-2, GEEN-3, } \\
\text { GEEN-4, GEEN-5 e GEEN-6 }\end{array}$ \\
\hline $\begin{array}{l}\text { MBA em Finanças, Controladoria e } \\
\text { Auditoria }\end{array}$ & $\begin{array}{c}\text { Em fase de } \\
\text { conclusão }\end{array}$ & 3 & FCA-1 e FCA-2 \\
\hline MBA em Logística e Supply Chain & $\begin{array}{c}\text { Em fase de } \\
\text { conclusão }\end{array}$ & 1 & GNA-1 LOG-2 e LOG-3 \\
\hline $\begin{array}{l}\text { MBA em Administração de } \\
\text { Empresas de Transporte Aéreo }\end{array}$ & Concluído & 1 & AETA-1 \\
\hline $\begin{array}{l}\text { MBA em Gestão de Negócios } \\
\text { Automotivos Concluído }\end{array}$ & & 2 & \\
\hline
\end{tabular}

Quadro 3 Participantes da pesquisa de acordo com o tipo de MBA. Fonte: Elaborado pelas autoras com base nas entrevistas.

\section{APRESENTAÇÃO E DISCUSSÃO DOS RESULTADOS DA PESQUISA}

A análise dos dados coletados foi organizada em torno de três categorias tendo em vista o alcance dos objetivos de pesquisa inicialmente propostos, relativos às características gerais dos cursos, ao que os alunos aprenderam e aos impactos (de curto prazo) em suas carreiras.

\subsection{CARACTERÍSTICAS GERAIS DOS CURSOS REALIZADOS SEGUNDO A VISÃO DOS PARTICIPANTES}

Foi possível identificar nas falas dos participantes que os elementos presentes nessa categoria exercem um papel importante para a aprendizagem. Os temas que emergiram focam os aspectos gerais dos programas, disciplinas e estrutura do curso, a metodologia e eventos focados na realidade, as formas de avaliação, os critérios de seleção de alunos e composição da turma, o alinhamento entre os conteúdos das disciplinas e as atividades de trabalho e a opinião dos alunos sobre o que mais contribuiu para sua aprendizagem.

Quanto aos aspectos gerais, disciplinas e estrutura do curso, os elementos que apareceram nessa subcategoria demonstram que os participantes avaliam que os cursos 
atingiram seus objetivos. No geral, apesar de algumas críticas, a reação foi positiva, como verificado no depoimento abaixo:

\begin{abstract}
Assim, a sequência eu achei bem interessante porque foi separado em três módulos praticamente que era de planejamento, de orçamento e de plano de negócios. [...]. Aí no final você fazia workshop de um planejamento estratégico de uma empresa utilizando os módulos que você aprendeu. Então como se eu fosse montar uma empresa de TI, por exemplo, aí eu ia fazer planejamento, vendas, como que eu ia distribuir os produtos, como que eu ia fazer a parte de marketing [...]. Então isso foi bem interessante porque veio te dando a visão de pedaço por pedaço para formar uma empresa mesmo, um negócio. (GEEN-5).
\end{abstract}

Os participantes abordaram também os seguintes aspectos: a aplicabilidade das disciplinas, a pressão de tempo, o intervalo entre a realização de uma disciplina e outra, a distância entre disciplinas complementares, disciplinas que agregaram mais conhecimento do que outras, tendo em vista o perfil e histórico profissional do indivíduo. Entende-se que esses aspectos devem ser pontuados, pois acabam impactando na aprendizagem e retenção, segundo opinião dos próprios participantes.

Seis participantes abordaram a questão dos prazos e a pressão de tempo para cumprir as demandas do curso, uma vez que conciliam o curso com o trabalho. Em sua opinião, essa pressão de tempo é um fator que prejudica a aprendizagem, pois dificulta o processo de reflexão. Com relação à falta de tempo, os resultados corroboram aqueles de Ruas e Comini (2007) que atestam que o processo de transferência de aprendizagem é dificultado quando o aluno considera que as demandas do trabalho consomem muito tempo, não permitindo que ele reflita e articule a teoria e a prática. No entanto, é importante estar atento para a ideia de Gosling e Mintzberg (2006) de que o aluno de MBA deve estar trabalhando para identificar na organização as oportunidades para transferir a aprendizagem, ou seja, aplicar o conhecimento obtido no curso.

Foi possível identificar que alguns participantes avaliaram algumas disciplinas como superficiais, e outros que disseram que o aprofundamento em uma disciplina específica depende da iniciativa do próprio aluno. Sete participantes falaram especificamente de disciplinas que precisariam ser alteradas, incluídas ou excluídas. A falta de disciplinas voltadas à gestão de pessoas também emergiu nas falas dos participantes.

As falas dos participantes também revelam aspectos relativos às metodologias $\mathbf{e}$ eventos focados na realidade e que foram adotados nos cursos: possibilidade de troca com colegas e professores dentro e fora de sala de aula, a elaboração de trabalhos em grupo, 
aplicação de jogos de empresas (disciplinas denominadas Business Simulation), o uso de casos, aulas expositivas e o trabalho de conclusão de curso (TCC).

Com relação aos jogos de negócios (Business Simulation), os participantes consideraram sua utilização como um recurso didático importante, que consolida aspectos conceituais. Entendem o jogo como uma ferramenta focada na realidade, que alia teoria e prática. Apesar dos jogos serem muito centrados em tomadas de decisão e resultados de curto prazo, eles comentaram que tiveram a oportunidade de desenvolver, por meio deles, visão estratégica e soft skills, como liderança, trabalho em equipe e negociação. Relataram ainda que o Business Simulation foi realizado por meio de simulação online, abrangendo uma visão integrada das funções de uma empresa, operando em um ambiente competitivo, com decisões de Marketing e Vendas, Finanças, Operações, Recursos Humanos, etc.

Oito participantes abordaram o Business Simulation em diferentes aspectos, trazendo elementos que o relacionam à aprendizagem. O trecho a seguir ilustra essas ideias:

\begin{abstract}
Mas ele te dava uma visão de negócio assim absurda e você mexia com todos os elos, você mexia com preço, mexia com produção, mexia com transporte, [...]. Fantástico. [...] na apresentação a gente viu o quanto a gente estava maduro com o negócio, como a gente aplicou a teoria na prática, como a gente se blindou em relação ao mercado, enfim, pensando tanto na sua empresa quanto nos concorrentes, [...]. E outra coisa também que os jogos te proporcionam é como é difícil você trabalhar com pessoas diferentes. Então a hora de você pensar em uma sociedade ou algo do gênero você tem que pensar muito bem nas pessoas que você bota do lado porque cria um conflito muito pesado e que eu não esperava. Eu nunca pensei nisso. E esses jogos me abriram a visão. (LOG-2).
\end{abstract}

No entanto, dois participantes questionaram a validade do jogo de empresas em relação ao planejamento e resultados. Para eles, o fato de ser um simulador torna-o distante do mundo real, permitindo que o aluno cometa erros, implicando até mesmo na quebra da empresa.

A troca com os colegas e com os professores dentro e fora de sala de aula e a elaboração de trabalhos em grupo apareceu na fala de oito participantes. O trecho a seguir ilustra esse aspecto:

Foi esta mescla. Foi justamente você ter aula expositiva, você ter uma apresentação dos trabalhos. Eu tive a oportunidade de fazer trabalho com várias pessoas. A apresentação dos trabalhos em cada matéria. Eu vi o pessoal da Dow apresentando, eu vi o pessoal da Visa apresentando, do Walmart apresentando e cada um mostrando um pouco da sua característica, a história da empresa e isso acrescentou bastante, porque você tem uma aula expositiva, teórica, mas você tem um conteúdo aplicado à prática. Como é que funciona para cada um deles e isso foi bastante interessante. (LOG-1). 
GEEN-6 e GEEN-4 consideraram que, embora os professores estimulassem as discussões em sala de aula, os alunos não participavam tão ativamente. GEEN-4 apontou que os trabalhos em grupo contribuíram para a aprendizagem, mas criticou o comprometimento de alguns colegas.

Sete participantes comentaram sobre o uso de estudos de caso como recurso didático.

O mais importante nas metodologias são as análises dos casos reais. A gente tem várias coisas que foram feitas, vários problemas que tivemos no passado que a gente pode replicar para a realidade hoje. Então para mim na metodologia o mais válido foi os cases reais, a gente sai um pouco do teórico e trabalha mais o prático. Isso para mim foi a melhor coisa que teve no curso da IES. [...]. Eu acho que esses são um dos melhores pontos da metodologia da IES. (LOG-2).

Mintzberg (2004) questiona a adoção dos estudos de caso como método didático. Para ele, o estudo de caso é uma simplificação do ponto de vista didático, pois os dados são estruturados de forma a se relacionarem às áreas funcionais. Porém, sete participantes o avaliaram de forma positiva para o aprendizado. Destacaram que os casos são oportunidades de ver a teoria na prática e refletir sobre essa, analisando a realidade e os desafios de diversas empresas, muitos dos quais semelhantes aos encontrados em suas próprias organizações.

Em relação ao TCC, os participantes consideraram que é uma oportunidade de consolidar os conceitos teóricos vistos nas diversas disciplinas ao longo do curso e transformá-los em um Plano ou Projeto, com aplicabilidade real, ou não, ao negócio da empresa, pois segundo as regras da IES, não é mandatório que o TCC seja focado na realidade da empresa onde o participante trabalha. Apesar dessa regra, nove participantes afirmaram que desenvolveram o TCC com aplicação às necessidades e realidade da empresa, escolhendo o tema por conta própria, sem interferência da organização.

Retomando os princípios de sustentação pedagógica voltados à educação gerencial, propostos por Gosling e Mintzberg (2006), foi possível detectar nas falas dos participantes, a presença de três princípios: o pensamento reflexivo em sala de aula, os impactos para a organização gerados por esse pensamento reflexivo e o processo de aprendizagem interativo. Segundo os participantes da pesquisa, esses princípios estiveram presentes nos estudos de caso, na troca com os colegas e professores em sala de aula e no Business Simulation.

Com base nos depoimentos dos alunos, também foi possível identificar a presença de alguns dos princípios do construtivismo nas metodologias de ensino adotadas nos cursos, como proposto por Pham (2011). O Quadro 4 ilustra este aspecto. 


\begin{tabular}{|l|l|}
\hline \multicolumn{1}{|c|}{ Princípio do Construtivismo } & \multicolumn{1}{c|}{ Metodologias adotadas nos cursos } \\
\hline $\begin{array}{l}\text { Apoiar a construção colaborativa do conhecimento } \\
\text { por meio da negociação social e não da competição } \\
\text { entre os alunos }\end{array}$ & $\begin{array}{l}\text { Troca com colegas e professores em sala de aula e } \\
\text { fora da sala de aula }\end{array}$ \\
\hline $\begin{array}{l}\text { Promover o estímulo à reflexão sobre as } \\
\text { experiências }\end{array}$ & $\begin{array}{l}\text { Troca com colegas e professores em sala de aula e } \\
\text { fora da sala de aula e Estudo de Casos }\end{array}$ \\
\hline $\begin{array}{l}\text { Encorajar a construção do conhecimento ao invés } \\
\text { da reprodução do conhecimento }\end{array}$ & $\begin{array}{l}\text { Troca com colegas e professores em sala de aula e } \\
\text { fora da sala de aula }\end{array}$ \\
\hline Desenvolver tarefas autênticas num contexto real & Trabalhos e TCC \\
\hline $\begin{array}{l}\text { Propiciar ambientes de aprendizagem próximos às } \\
\text { configurações do mundo real e não sequências pré- } \\
\text { determinadas de instrução }\end{array}$ & Jogos de Negócios \\
\hline $\begin{array}{l}\text { Evitar excesso de simplificação e representar a } \\
\text { complexidade da realidade na prática }\end{array}$ & Jogos de Negócios e Estudo de Casos \\
\hline
\end{tabular}

Quadro 4 Princípios do Construtivismo nos cursos.

Fonte: Elaborado pelas autoras, com base em Pham (2011).

Dentre as metodologias adotadas nos cursos e abordadas pelos participantes, aquelas avaliadas como as que mais contribuíram para sua aprendizagem foram: a troca de experiências, o Business Simulation, a elaboração e apresentação de trabalhos, as aulas e os casos. Foi possível identificar que não há um consenso entre os alunos de um mesmo MBA em relação a esse aspecto.

Com relação aos critérios de seleção de alunos e composição da turma, foi analisada a opinião dos alunos quanto ao momento de carreira e maturidade profissional para cursar o MBA. Nas entrevistas, eles abordaram questões relativas ao seu perfil e o dos colegas da turma. Para eles, as discussões em classe, a elaboração de trabalhos em grupo e a seriedade na condução do curso ficam prejudicadas quando há alunos sem experiência profissional relevante ou que fazem o curso apenas para melhorar o currículo. Consideram a necessidade de experiência profissional e maturidade como pré-requisitos para um curso dessa natureza:

Eu vou falar da minha experiência, eu fui para o MBA e o que era dado eu já tinha vivido então eu conseguia introduzir aquilo para o meu mundo e agregar. Então eu acho que a parte de triagem de quem vai fazer o MBA é muito importante, por que eu acho que se eu tivesse feito no começo da minha carreira ele não agregaria tanto como agregou hoje. (GEEN-3).

De acordo com Gosling e Mintzberg (2006), a educação gerencial deveria ser restrita aos gerentes com experiência, os quais deveriam ser selecionados com base no desempenho da função gerencial. Para Mintzberg (2004), os MBAs ensinam as pessoas erradas, que são profissionais sem experiência profissional. Os participantes da pesquisa reforçam que os critérios para seleção dos alunos deveriam levar em conta a experiência profissional e as posições ocupadas na organização, reforçando as ideias de Mintzberg (2004). Eles entendem 
que turmas homogêneas em termos de experiência profissional e heterogêneas em termos de segmentos e áreas de atuação e formação acadêmica de origem enriquecem as discussões dentro e fora da sala de aula e contribuem para a aprendizagem.

Por ser um curso de especialização Lato sensu, o MBA deve ter avaliação por meio de provas presenciais em todas as disciplinas, além do TCC. Em seus depoimentos, os participantes afirmaram que as provas, em alguns casos, não avaliam a aprendizagem, mas também não conseguem pensar em alternativas para sua substituição, pois acabam sendo um incentivo para estudarem mais. Os trabalhos, mais especificamente em grupo, são as formas de avaliação preferidas pelos participantes. Os resultados corroboram as ideias de Monks e Walsh (2001), que defendem a ideia de que, nos MBAs, deve haver mudanças na forma de ensinar, pois o público é composto por indivíduos adultos, com experiência profissional e que devem ter uma abordagem crítica ao conteúdo. Para esses autores, deve haver uma substituição da abordagem do ensino focada no desempenho para o ensino focado no entendimento, na qual o aluno deve buscar aplicar o conhecimento e habilidades aprendidos em situações variadas, em detrimento de buscar apenas a obtenção de boas notas. Para isso, propõem mudanças nas formas de avaliação por reais oportunidades de aplicar o conteúdo do curso a problemas enfrentados nas organizações.

Em seus depoimentos, os participantes deram destaque às disciplinas que estavam mais alinhadas às suas atividades no trabalho, aprofundando esse tema em diversas partes da entrevista. Ainda com relação às disciplinas, é possível perceber que sua avaliação varia em função do conhecimento prévio que eles têm sobre determinado assunto. Algumas podem não abordar conteúdos novos para certos alunos. Eles podem avaliar uma disciplina como básica ou superficial, em função de trabalhar diretamente com aquele tema, ler e buscar conhecimentos por iniciativa própria, ter feito cursos de curta duração sobre o tema na empresa ou em instituições de ensino ou, ainda, ter feito outro MBA, no qual aquela disciplina ou outra similar tenha sido ministrada. Diversas disciplinas foram destacadas por 12 participantes, alinhadas com suas necessidades, seus desafios no trabalho e sua atuação direta na empresa, incluindo o incentivo de alguns professores para a aplicação do conteúdo. Em alguns casos, praticamente todas as disciplinas estavam alinhadas ao trabalho. Ao analisar que o conteúdo da disciplina está alinhado com suas demandas e necessidades de trabalho, o participante reflete sobre oportunidades para uma aplicação. Todos os participantes que abordaram a questão do alinhamento citaram as hard skills. As disciplinas consideradas soft 
skills apareceram em seis depoimentos, incluindo a ressalva de que eram muito teóricas ou de que não haviam acrescentado nada de novo em termos de conteúdo.

Os depoimentos dos alunos com relação às disciplinas corroboram as ideias de Mintzberg (2004) e Herrington (2010). Para Mintzberg (2004), um dos maiores problemas associados aos programas de MBA é a priorização das hard skills em detrimento da necessidade de desenvolvimento das soft skills, de grande importância na prática da gestão. Segundo Herrington (2010), os alunos que concluem o MBA são muito focados em aspectos financeiros de curto prazo e carecem de habilidades de comunicação, relacionamento interpessoal e formação de equipes.

\subsection{APRENDIZAGEM}

Neste item, descreve-se "o quê" os participantes consideram que foi aprendido no curso, no aspecto profissional e pessoal, por meio das situações vivenciadas durante a realização do mesmo. Enquanto alguns abordaram de forma geral o que aprenderam no curso como um todo, outros descreveram o que aprenderam em detalhes, inclusive relacionado com algumas disciplinas específicas. Os participantes abordaram a aprendizagem falando sobre como estavam utilizando a mesma no trabalho, em alguns casos, por meio da "aplicação".

\section{No aspecto profissional, 10 participantes descreveram o que aprenderam no} curso como um todo. Dentre os resultados dessa aprendizagem, é possível destacar: como fazer a gestão de uma empresa, como planejar melhor, tomar decisões, o desenvolvimento de uma visão crítica sobre análise de números, onde buscar informações tanto do ponto de vista teórico quanto de fontes do mercado e desenvolver novos conhecimentos, aprofundar-se e "pensar fora da caixa" e como enxergar a empresa como um todo, em uma perspectiva de visão sistêmica, a atualização sobre várias coisas que estavam acontecendo no mercado, o desenvolvimento de competências técnicas de gestão para o seu negócio. Nas soft skills, o curso lhe ofereceu as bases necessárias para ser um líder melhor, a empatia (colocar-se no lugar do outro, principalmente subordinados e fornecedores), o desenvolvimento das habilidades de comunicação e negociação. As disciplinas relativas ao aspecto profissional, citadas pelos participantes com maior frequência foram: empreendedorismo, disciplinas relacionadas à gestão contábil e financeira, incluindo análise de balanços e de demonstrativos financeiros em geral, negociação, gestão de operações com foco para análise de indicadores. 
No aspecto pessoal, foi possível identificar elementos que não estão diretamente relacionados ao trabalho que os participantes executam nas organizações. Sete participantes descreveram o que aprenderam no curso no aspecto pessoal, na perspectiva do curso como um todo. Alguns comentaram que o curso lhes proporcionou um engrandecimento pessoal, transformando-os em pessoas mais completas e melhores, pensando em uma sociedade e país melhores. Segundo GEEN-5:

[...] Então eu acho que foi mais pessoal do que mesmo profissional. Mas me deu uma visão pessoal assim num todo que eu não tinha. Então me agregou bastante.

As disciplinas mais citadas no aspecto pessoal foram: negociação, economia e ética e desenvolvimento sustentável. Para os participantes, elas foram responsáveis por mudá-los como pessoa e, partir daí, passaram a adotar novos comportamentos dentro e fora do trabalho.

Dentre as críticas aos MBAs, houve consenso quanto à necessidade de mudanças em seu curriculum, englobando questões multidisciplinares, éticas e práticas, que reflitam os desafios e a complexidade dos negócios enfrentados pelos líderes atuais e não somente as questões e aspectos financeiros de curto prazo.

É possível concluir, com base nos depoimentos dos participantes que elencaram as mudanças no aspecto pessoal, que a inclusão de disciplinas voltadas às questões humanas nos negócios é importante, reafirmando as ideias de Monks e Walsh (2001), Bennis e O’Toole (2005) e Herrington (2010). Os resultados aqui encontrados também corroboram aqueles encontrados na pesquisa de Ruas e Comini (2007), na qual os alunos entenderam que um dos impactos dos programas de MBA e Pós-graduação estava associado ao desenvolvimento de sua capacidade intelectual, crescimento pessoal e profissional.

\subsection{IMPACTOS NA CARREIRA DO ALUNO}

Com relação aos impactos na carreira, dos 13 participantes do estudo, quatro mudaram de emprego ao longo do curso: GEEN-2, GEEN-3, GEEN-6 e AETA-1. A análise de suas falas indicou que o fato de estarem fazendo um curso dessa natureza em uma instituição de ensino reconhecida reflete em um diferencial competitivo, que contribuiu para sua contratação em novas organizações.

GEEN-2 e AETA-1 mudaram de empresa, mas continuaram no mesmo segmento, respectivamente, de tecnologia e de transportes aéreos. GEEN-6 era Diretor de Marketing em uma multinacional de artigos de luxo e passou para Diretor de Marketing em uma ONG 
voltada a projetos de conservação ambiental. O caso de GEEN-3 é distinto, pois ele saiu de empresa multinacional para abrir seu próprio negócio.

LOG-1 e GEEN-1 não mudaram de emprego, mas abordaram a questão da empregabilidade, apontando para o diferencial do curso no curriculum:

Para efeito também de curriculum eu percebi que depois que eu entrei na IES e coloquei lá no Linkedin, por exemplo, tive muitas propostas de emprego. Realmente a Instituição tem um nome muito forte então eu já percebi muitas empresas me consultando, me ligando, me questionando. (LOG-1).

Recebi propostas de emprego depois do MBA. Graças a Deus nunca parou. Olha, eu ainda não fui atrás. De vez em quando sempre pinta alguém interessado. Não mudou essa frequência. Talvez para eu ter um retorno mais concreto disso eu teria que ir atrás e ver como está minha aceitação. (GEEN-1).

Contrariamente, GEEN-3 e FCA-2 afirmaram que o MBA por si só não garante empregabilidade, nem promoções:

[...] Eu acho que o MBA por si só, você ter um diploma é algo que ninguém vai olhar para você e achar que você trabalha melhor por que você tem o diploma. Isso é um fato comum que tem crescido no mercado hoje. As suas avaliações de como as pessoas te olham vão melhorar desde que haja resultado, desde que seu dia a dia tenha mudado realmente. [...]. Eu vejo muito isso nas empresas americanas que eu passei que eram muito focadas em resultado, você ter MBA em Harvard, se você não está gerando resultado nada mudou muito. (GEEN-3).

Então hoje, MBA na IES ou em outra Instituição de Ensino, qualquer um vai ter, vai virar uma obrigação, você vai brigar de igual para igual. Então se você ficar pensando que vai conseguir um emprego melhor, você vai ter que bater de frente com um monte de gente, você já está pensado errado. [...]. Você chega lá e tem mais cinquenta pessoas com o mesmo título. Antigamente ninguém tinha acesso e hoje está tendo de uma forma ou outra. Eu não vejo ninguém promovido, as pessoas que foram promovidas que estavam lá na turma, foi por que já estavam dentro da empresa, já existia uma estrutura ali. (FCA-2).

Alguns participantes abordaram que o fato de estarem fazendo o MBA gerou reconhecimento e respeito dentro da organização. Ademais, é possível inferir, conforme depoimentos abaixo, que a IES também exerceu influência nessa valorização:

O pessoal olhava e o fato de você estar fazendo MBA, estar fazendo alguma coisa sempre é visto com bons olhos. O pessoal me incentivava a fazer. (GEEN-2).

E hoje em dia você percebe, e eu acabo percebendo que eles vêm e começam a perguntar mais coisas e começam a te envolver em mais coisas que antes não envolviam e começam a fazer perguntas. (FCA-1).

Para mim é conhecimento, atualização, eu não olhar ele como "você vai ter uma posição melhor por causa disso" isso é automático, pelo fato das pessoas começarem a abrir as portas para mim, informações maiores começaram a vir para mim. Então veio automático e eu estou vendo dessa forma o MBA. (FCA-2). 


\section{CONSIDERAÇÕES FINAIS, LIMITAÇÕES DO ESTUDO E SUGESTÕES PARA ESTUDOS FUTUROS}

Esta pesquisa teve como objetivo ampliar a compreensão sobre o MBA a partir da perspectiva de alunos e ex-alunos pertencentes ao público-alvo ideal do MBA, segundo critérios defendidos por Henry Mintzberg. A partir da análise das descrições trazidas pelos participantes nas entrevistas, foi possível identificar seis pontos fundamentais.

O primeiro diz respeito à avaliação positiva dos alunos quanto ao desenho e à estrutura dos cursos em geral e a aprovação quanto às diferentes metodologias adotadas, principalmente aquelas com abordagens práticas. Destaca-se que nos cursos, houve a adoção dos princípios do construtivismo (PHAM, 2011) e dos princípios de sustentação pedagógica voltados à educação gerencial de Gosling e Mintzberg (2006).

O segundo ponto está associado ao fato do aprendizado adquirido estar relacionado aos aspectos pessoal e profissional, destacando-se a gestão de uma empresa, indo contra as ideias de Mintzberg (2004), que considera que o MBA apenas treina nas funções do negócio.

$\mathrm{O}$ terceiro ponto também se relaciona às aprendizagens adquiridas nos aspectos profissional e pessoal, que ampliaram o entendimento dos participantes em relação à complexidade inerente ao ambiente de negócios contemporâneo. Foi possível perceber ainda que a aprendizagem no plano pessoal acaba exercendo impacto no aspecto profissional.

Com relação ao desenho dos cursos e à aprendizagem - quarto ponto a ser destacado os resultados encontrados, revelando o predomínio das hard skills, corroboram as ideias de Mintzberg (2004) e Herrington (2010) quanto às diferenças entre as hard skills e as soft skills. Neste sentido, é necessário avaliar se o MBA é o programa mais adequado para o desenvolvimento de determinadas soft skills, que demandam diferentes metodologias de ensino, avaliação e aplicação no trabalho.

Um quinto ponto a ser focado refere-se à avaliação dos participantes no que diz respeito ao perfil da turma e de como esse perfil exerce um impacto significativo na troca de experiências e na aprendizagem. Os alunos reforçaram, de forma expressiva, as opiniões de Mintzberg (2004) quanto ao público-alvo do MBA ser formado por profissionais com experiência gerencial ou experiência profissional relevante. Neste sentido, o papel do aluno é fundamental na aprendizagem em sala de aula e na aplicação desta no trabalho. Neste contexto, foi possível detectar que os participantes reforçaram o seu papel enquanto alunos e enquanto profissionais, sem mencionar o acompanhamento das empresas onde trabalham. 
Como sexto ponto, examina-se o fato dos impactos de curto prazo do MBA em suas carreiras não parecerem significativos, ou seja, o título de MBA não garante por si só, o desenvolvimento na carreira e a empregabilidade. No Brasil, onde houve uma proliferação da sigla MBA, esse fato parece ter-se tornado mais relevante, reforçando as ideias de Ruas (2003) e Wood Jr. e Paula (2004).

Não foi possível identificar diferenças significativas nas avaliações de cada curso individualmente. Mesmo sendo cursos com diferentes especializações, as avaliações foram semelhantes. É possível concluir que esse resultado seja em função do perfil dos participantes e do desenho dos cursos na IES.

Este estudo apresenta algumas limitações. A primeira está relacionada à impossibilidade de generalização de seus resultados, tendo em vista a adoção da abordagem qualitativa. Ao mesmo tempo em que a impossibilidade de generalização se apresenta como uma limitação, cabe destacar que a pesquisa qualitativa não tem como objetivo generalizar resultados, mas compreender um fenômeno ou processo, a partir da perspectiva de seus participantes (MERRIAM, 1998). A segunda diz respeito aos participantes da pesquisa, pois todos são da mesma instituição de ensino, restritos a cinco cursos e com um perfil peculiar, principalmente no tocante à experiência profissional e experiência como gestor.

Neste sentido, ao se considerar as diferenças dos MBAs no Brasil em relação ao modelo norteamericano, sugerem-se pesquisas qualitativas ou quantitativas com alunos de outras instituições de ensino menos expressivas em termos de reconhecimento no mercado, alunos de MBAs generalistas, alunos mais jovens e/ou recém-formados, alunos de Mestrados Profissionais e alunos de MBAs que se aproximam do modelo norteamericano. Para avaliar o impacto na carreira e empregabilidade, seriam necessárias pesquisas longitudinais, ou pesquisas com alunos que já concluíram o MBA há mais tempo, comparando os resultados com aqueles aqui encontrados. Ao se considerar as diferenças dos MBAs no Brasil em relação ao modelo norteamericano, os resultados dessas pesquisas poderão trazer elementos que auxiliem na reflexão acerca da pertinência e validade do modelo brasileiro e forneçam pistas para melhorias no mesmo.

\section{REFERÊNCIAS}

ASSOCIATION OF MASTERS IN BUSINESS ADMINISTRATION. MBA Accreditation guidelines and criteria. Disponível em: 
http://www.mbaworld.com/en/Accreditation/Become-an-accredited-businessschool.aspx. Acesso em: 30/05/2013.

ACITO, F.; MCDOUGALL, P. M.; SMITH, D. C. One hundred years of excellence in business education: What have we learned? Business Horizons, v.51, n.1, p.5-12, 2007.

BARUCH, Y.; LEEMING, A. The added value of MBA studies - graduates' perceptions. Personnel Review, v.30, n.5, p.589-601, 2001.

BENNIS, W. G.; O'TOOLE, J. How business schools lost their way. Harvard Business Review, v.83, n.5, p.96-104, 2005.

BROCKLERURST, M.; STURDY, A.; WINSTANLEY, D.; DRIVER, M. Whither the MBA? Factions, Fault Lines and the future. Management Learning, v.38, n.4, p.379-388, 2007.

CHENG, E. W. L. Test of the MBA knowledge and skills transfer. International Journal of Human Resource Management, v.11, n.4, p.837-852, 2000.

CRUZ, J. F. P. Percepção dos alunos sobre o impacto de curto prazo dos cursos de MBA em suas carreiras. São Paulo, 2013. 100 f. Dissertação (Mestrado Profissional em Administração). Escola de Administração de Empresas de São Paulo, da Fundação Getulio Vargas.

GIL FLORES, J. Análisis de dados cualitativos. Aplicaciones a la investigación educativa. Barcelona: PPU, 1994.

GODOY, A. S. Fundamentos da pesquisa qualitativa. In: TAKAHASHI, A. R. W. Pesquisa qualitativa em administração: fundamentos, métodos e usos no Brasil. São Paulo: Atlas, 2013. p.35-49.

GOSLING, J.; MINTZBERG, H. Management Education as if both matter. Management Learning, v.37, n.4, p.419-428, 2006.

GUPTA, P. B.; SAUNDERS, P. M.; SMITH, J. Traditional Master of Business Administration (MBA) Versus the MBA with specialization: A disconnection between what business schools offer and what employers seek. Journal of Education for Business, v.8, n.6, p.307-312, jul./ago. 2007.

HAY, A. Seeing differently: putting MBA learning into practice. International Journal of Training and Development, v.10, n.4, p. 291-297, 2006.

HERRINGTON, J. D. MBA: Past, Present and Future. Academy of Educational Leadership Journal, v.14, n.1, p.63-76, 2010.

KING, N. Using templates in the thematic analysis of text. In: CASSELL, C.; SYMON, G. Essential guide to qualitative methods in organizational research. London: Sage Publications, 2004. p.256-270. 
MERRIAM, S. B. Qualitative research and case study applications in education. 2. ed. San Francisco: Jossey-Bass, 1998.

MINTZBERG, H. Managers not MBAs: a hard look at the soft practice of managing and management development. London: Prentice Education, 2004.

MONKS, K.; WALSH, J. S. The role of postgraduate education in management development. Journal of European Industrial Training. v.25, p.148-156, 2001.

PFEFFER, J.; FONG, C. T. O fim das escolas de negócios. Revista de Administração de Empresas - RAE, v.43, n.2, p.11-28, 2003.

PHAM, N. T. P.; SEGERS, M. S. R,; GIJSELAERS, W. H. The Effect of the Trainees's Perception of the Training Design on Transfer of Training: The Case of Master of Business Administration (MBA) of Vietnam. In: BOSSCHE, P.; GIJSELAERS, W. H.; MILTE, R. (Eds.) Advances in Business Education and Training, (Dordrecht: Springer), p.215-233, 2011.

RUAS, R. Mestrado modalidade profissional: em busca de identidade. Revista de Administração de Empresas - RAE, v.43, n.2, p.55-63, 2003.

RUAS, R.; COMINI, G. M. Aprendizagem e desenvolvimento de competências: articulando teoria e prática em programas de pós-graduação em formação gerencial. Cadernos EBAPE, v. 5, Edição Especial, 2007.

RUBIN, ROBERT S.; DIERDORFF, ERICH C. How Relevant is the MBA? Assessing the Alignment of Required Curricula and Required Managerial Competencies. Academy of Management Learning \& Education, v.8, n.2, p.208-224, 2009.

WOOD JR., T.; PAULA, A. P. Pop-management: MBAs no Brasil. Séries Relatórios de Pesquisa, São Paulo, Eaesp/FGV, n. 25, 2002.

WOOD JR., T.; PAULA, A. P. O Fenômeno dos MPAs Brasileiros: Hibridismo, Diversidade e Tensões. In: Revista de Administração de Empresas - RAE, São Paulo, v.44, n.1, p.116129, 2004.

ZHAO, J. J.; TRUELL, A. D.; ALEXANDER, M. W.; HILL, I. B. "Less success than meets the eye?" The impact of master of business administration education on graduates' careers. Journal of Education for Business, v.81, n.5, p.261-268, May/June 2006. 